\title{
Black Carbon Emissions from Associated Natural Gas Flaring
}

Supporting Information

Cheryl L. Weyant, Paul B. Shepson, R. Subramanian, Maria O. L. Cambaliza, Alexie Heimburger, David McCabe, Ellen Baum, Brian H. Stirm, and Tami C. Bond

\section{Table of Contents}

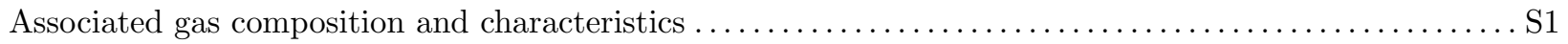

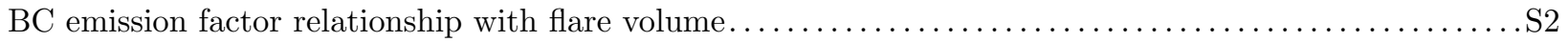

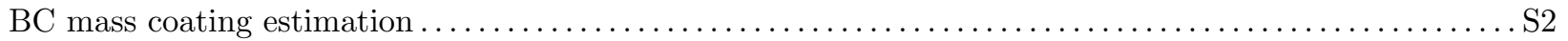

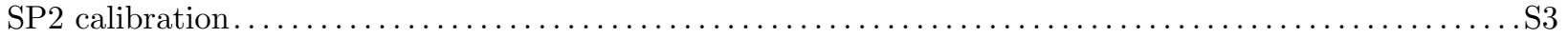

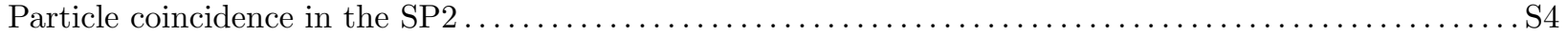

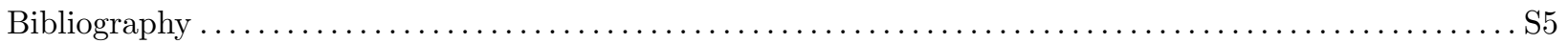

Figures and Tables

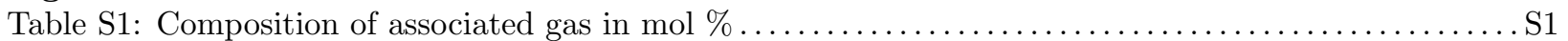

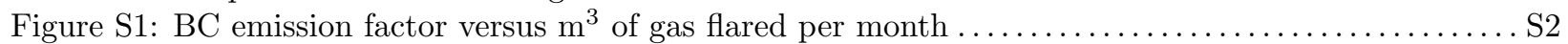

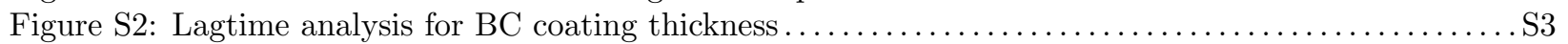

Figure S3: Size distribution of particle number and mass detected in the SP2 for flares on March $25 \ldots . . \mathrm{S} 4$

Figure S4: Coincidence corrected number and mass concentrations of BC measured in the SP2 .......S4 


\section{Associated gas composition and characteristics}

Table S1: Composition of associated gas in mol \%. The percent carbon is the mass of carbon divided by the mass of the fuel including $\mathrm{H}_{2} \mathrm{O}, \mathrm{CO}_{2}$, and $\mathrm{N}_{2}$. The percent carbon of the hydrocarbons (HC) excludes these gases. ${ }^{1}$ Hypothetical gas compositions used in Caulton et. al. (2014) [4. ${ }^{2}$ Approximated gas composition in Haynesville (HV), Antrim (Ant), New Albany (NA), Fayetteveille (FV), Marcellus (Mar), and Barnett (Bar) formations [3]. ${ }^{3}$ Average gas composition in the Bakken formation, ND as tabulated by EERC [16].

\begin{tabular}{|c|c|c|c|c|c|c|c|c|c|c|}
\hline & $\operatorname{High}^{1}$ & $\mathrm{Med}^{1}$ & Low $^{1}$ & $\mathrm{HV}$ & Ant & $\mathrm{NA}$ & $\mathrm{FV}$ & Mar & Bar & Bakken \\
\hline methane & 1.000 & 0.800 & 0.600 & 0.950 & 0.620 & 0.899 & 0.973 & 0.852 & 0.868 & 0.577 \\
\hline ethane & 0.000 & 0.100 & 0.200 & 0.001 & 0.042 & 0.011 & 0.010 & 0.113 & 0.067 & 0.199 \\
\hline propane & 0.000 & 0.050 & 0.120 & 0.000 & 0.011 & 0.011 & 0.000 & 0.029 & 0.020 & 0.113 \\
\hline n-butane & 0.000 & 0.030 & 0.050 & & & & & & & 0.028 \\
\hline isobutane & & & & & & & & & & 0.010 \\
\hline n-pentane & 0.000 & 0.020 & 0.030 & & & & & & & 0.006 \\
\hline isopentane & & & & & & & & & & 0.004 \\
\hline hexane & & & & & & & & & & 0.002 \\
\hline heptane & & & & & & & & & & 0.001 \\
\hline octane & & & & & & & & & & 0.000 \\
\hline nonane & & & & & & & & & & 0.000 \\
\hline nitrogen & & & & 0.001 & 0.290 & & 0.007 & 0.003 & 0.029 & 0.052 \\
\hline carbon dioxide & & & & 0.048 & 0.038 & 0.079 & 0.010 & 0.004 & 0.017 & 0.006 \\
\hline water & & & & & & & & & & 0.000 \\
\hline \% Carbon & & & & 0.712 & 0.506 & 0.691 & 0.736 & 0.751 & 0.719 & 0.727 \\
\hline \% Carbon $\mathrm{HC}$ & 0.749 & 0.761 & 0.773 & 0.749 & 0.753 & 0.750 & 0.749 & 0.756 & 0.754 & 0.772 \\
\hline Density (g/m3) & 0.668 & 0.886 & 1.089 & 0.636 & 0.487 & 0.636 & 0.663 & 0.766 & 0.702 & 0.985 \\
\hline
\end{tabular}




\section{$\mathrm{BC}$ emission factor relationship with flare volume}

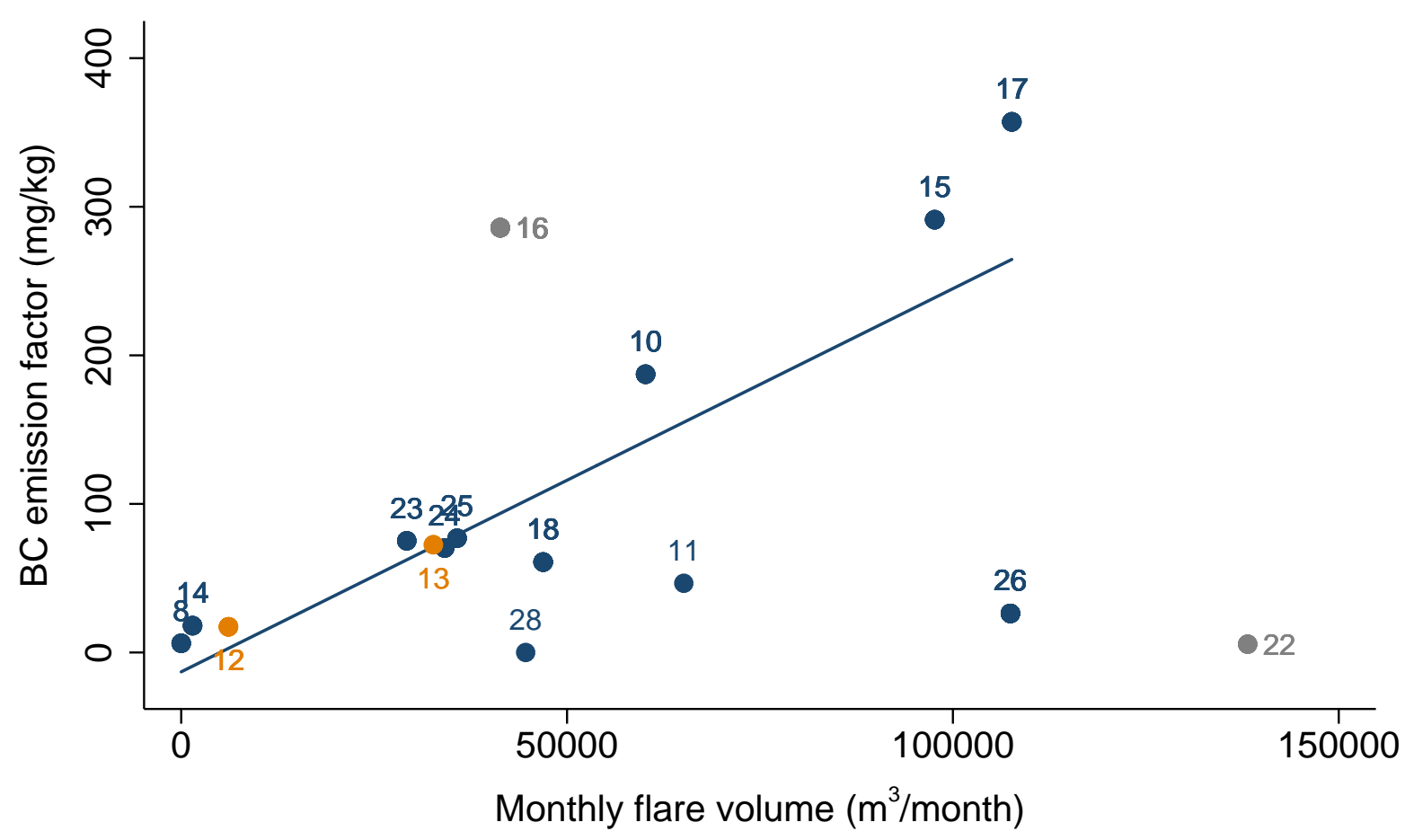

\begin{tabular}{lll}
\hline - Good & Fitted values (Good points) \\
\cline { 2 - 2 } - Incomplete data & Too far \\
\hline
\end{tabular}

Figure S1: BC emission factor versus $\mathrm{m}^{3}$ of gas flared per month, as reported in North Dakota Industrial Commission (NDIC) database [9]. The points represent the average BC emission factor for each flare. "Good" points are flares that could be clearly matched with well-by-well flaring data had complete flare volume information. "Incomplete data" points are those where information was not available for flaring volume from some wells connected to the flare. "Too far" data points were those where the GPS location was not within $200 \mathrm{~m}$ of the well heads listed in the NDIC database. The fit line uses only the "good" points.

\section{$\mathrm{BC}$ mass coating estimation}

The SP2 indicates that most particles are thinly coated. Figure S2 shows a distribution of the incandescent lag times for individual particles for a range of mass-equivalent particle diameters and can be used to indicate BC mixing state ("thickly-" or "thinly-coated" BC cores, as in Subramanian et al. 2010 [15].) Particles that have a lagtime near zero are considered to be thinly coated. The peak and most of the distribution is near zero in this example flight and is similar for the other flights. Few thickly-coated particles were observed. Thickly-coated particle have high lagtimes ( $2 \mu$ s and above), and approximately indicate particles with larger than $40 \mathrm{~nm}$ coating). Figure $\mathrm{S} 2$ represents both $\mathrm{BC}$ in flares and $\mathrm{BC}$ in background.

There could be some BC cores that have a BC-on-edge structure 13, though they are in the minority, and there is some uncertainty of such a classification based on SP2 operating conditions [14]. However, most of the flare $\mathrm{BC}$ emissions are thinly-coated, based on this analysis.

To estimate possible absorption enhancement due to particle coating, we estimated the amount of material in the plume that might condense on the BC. The fraction of condensable hydrocarbons relative to methane in the fuel gas was estimated using the fuel composition in the Bakken (Table S1) from EERC at measured 


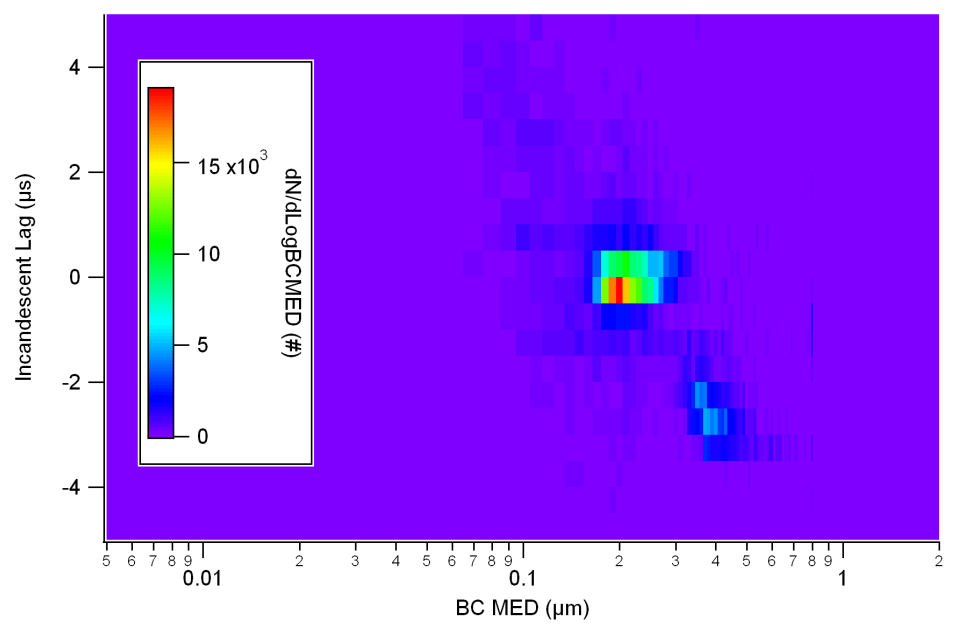

Figure S2: Lagtime analysis for BC coating thickness.

temperature in the plumes $\left(6.7 \pm 2.4{ }^{\circ} \mathrm{C}\right)$ at 0.07 grams condensable material per gram methane. The emission factor for $\mathrm{CH} 4(6 \mathrm{~g} / \mathrm{kg})$ measured here was multiplied by this ratio to determine an approximate emission factor for condensable hydrocarbons of approximately $0.4 \mathrm{~g} / \mathrm{kg}$ associated gas. The assumption is that the destruction removal efficiency does not vary between hydrocarbons.

The emission factor of condensable hydrocarbons is about three times greater by mass than that of BC. If this material condensed with an even distribution among BC particles of $200 \mathrm{~nm}$ diameter, the mass of each particle would increase by nine fg and each particle would be coated with a shell of $50 \mathrm{~nm}$. The absorption enhancement of such a particle, assuming a core-shell morphology, was determined using Mie theory as in Bond et al. (2006) using Matlab code developed by Mätzler [2, 7]. The predicted absorption enhancement was a factor of 1.4 .

\section{SP2 calibration}

BC mass was measured with the Single Particle Soot Photometer (SP2, Droplet Measurement Technologies) [12, 8). In line with community recommendations [1, the SP2 was calibrated using Fullerene soot, Lot Number L20W054, using the fullerene soot mobility density equation from Gysel et al. (2011) 5. In subsequent laboratory experiments, thermodenuded cookstove soot was size-selected by a DMA and then sampled by the SP2 and a Centrifugal Particle Mass Analyzer (CPMA, Cambustion) 10. The SP2 and CPMA masses agreed to within $10 \%$ (slope $1.08, \mathrm{R} 2=0.99$ ), indicating that the SP2 results presented in this paper are reasonably robust. (This calibration verification is presented in a manuscript currently under review at Aerosol Science and Technology: Saliba et al. (2016) [11.) The flow rate was measured in flight and was $180 \pm 50 \mathrm{cc} / \mathrm{min}$ throughout the entire sampling campaign.

The mass missed was based on a lognormal fit as in Subramanian et al. (2010) 15] and is calculated for the small accumulation mode particles. Most of the particles missed were below the detection limit of the instrument because of their small size. The mass of particles missed was approximately $0.5-2 \%$ and an upper limit of $5 \%$ was stated, given the approximate nature of the analysis. For accumulation mode particles on the larger end, the gain settings of the SP2 incandescence detectors were set so BC particles up to a mass-equivalent diameter of $\sim 800 \mathrm{~nm}$ (at a density of $1.8 \mathrm{~g} / \mathrm{cm} 3,480 \mathrm{fg}-\mathrm{BC} /$ particle) were detected properly by the SP2. As the BC size distributions show (Figure S3), all the flare emissions were well below this limit. The mass-equivalent diameter range observed was $0.05-0.8 \mu \mathrm{m}$.

\section{Particle coincidence in the SP2}

At the high source concentrations where our measurements were made, particle coincidence can be an issue. The code described in Holder et al. (2014) [6] was applied to correct for coincident particles. In 


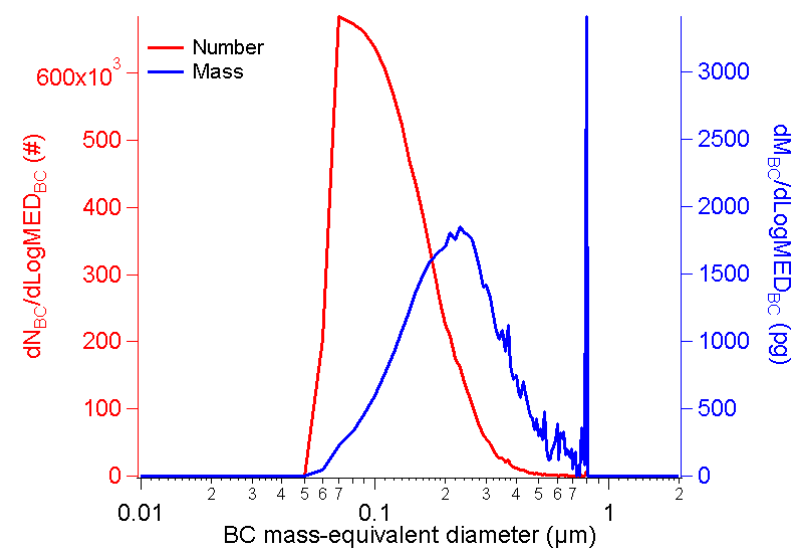

Figure S3: Size distribution of particle number and mass detected in the SP2 for flares on March 25.

that paper and in our analysis, the number concentration was more influenced by coincidence effects than the mass concentration (20\% increase in number concentration and $8 \%$ increase in mass concentration in Holder et al (2014)). In our analysis, the mass was increased by $5-10 \%$ in individual flare passes when coincidence was corrected for. Figure $\mathrm{S} 4$ shows the shift in mass-equivalent size distribution of BC cores as originally processed, and after reanalysis with the code from Holder et al. (2014). The size distribution from reanalysis has more particles of small mass. This is expected because the original analysis chooses the largest incandescent peak, so the retrieved coincident particles must have smaller masses. This also explains why even though the coincidence effect is significant for number concentrations above $2000 \mathrm{H} / \mathrm{cm}^{3}$, the effect on $\mathrm{BC}$ mass is much smaller. Our measurements produce BC emission factors that may be under-reported by up to $10 \%$ and MAC that may be over-reported by up to $10 \%$ due to saturation in the SP2.

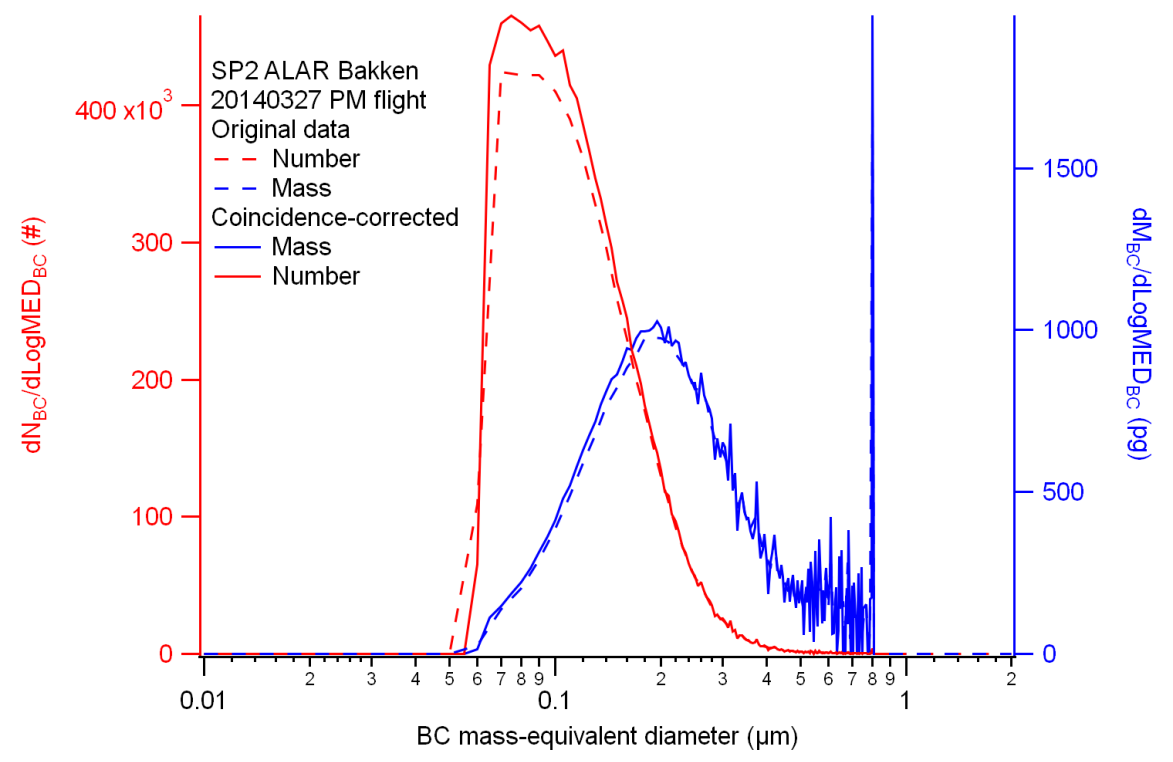

Figure S4: Coincidence corrected number and mass concentrations of BC measured in the SP2. 


\section{References}

[1] Baumgardner, D., Popovicheva, O., Allan, J., Bernardoni, V., Cao, J., Cavalli, F., Cozic, J., Diapouli, E., Eleftheriadis, K., Genberg, P., et Al. Soot reference materials for instrument calibration and intercomparisons: a workshop summary with recommendations. Atmospheric Measurement Techniques 5 (2012), 1869-1887.

[2] Bond, T. C., Habib, G., and Bergstrom, R. W. Limitations in the enhancement of visible light absorption due to mixing state. Journal of Geophysical Research: Atmospheres (1984-2012) 111, D20 (2006).

[3] Bullin, Keith and Krouskop, Peter. Composition variety complicates processing plans for US shale gas, Bryan Research and Engineering Inc.

[4] Caulton, D. R., Shepson, P. B., Cambaliza, M. O., McCabe, D., Baum, E., and Stirm, B. H. Methane destruction efficiency of natural gas flares associated with shale formation wells. Environmental Science \&3 Technology 48, 16 (2014), 9548-9554.

[5] Gysel, M., Laborde, M., Olfert, J., Subramanian, R., and Gröhn, A. Effective density of Aquadag and fullerene soot black carbon reference materials used for SP2 calibration. Atmospheric Measurement Techniques 4, 12 (2011), 2851-2858.

[6] Holder, A. L., Hagler, G. S., Yelverton, T. L., and Hays, M. D. On-road black carbon instrument intercomparison and aerosol characteristics by driving environment. Atmospheric Environment 88 (2014), 183-191.

[7] Mätzler, C. Matlab functions for Mie scattering and absorption, Institut fr Angewandte Physik, Research report no. 2002-08, Bern, Switzerland.

[8] Moteki, N., And Kondo, Y. Dependence of laser-induced incandescence on physical properties of black carbon aerosols: Measurements and theoretical interpretation. Aerosol Science and Technology 44, 8 (2010), 663-675.

[9] North Dakota Industrial Commission, Department of Mineral Resources, Oil and Gas Division. Historical monthly gas production and sales statistics. Date accessed: Feb 18, 2015.

[10] Olfert, J., And Collings, N. New method for particle mass classificationthe couette centrifugal particle mass analyzer. Journal of Aerosol Science 36, 11 (2005), 1338-1352.

[11] Saliba, G., Subramanian, R., Saleh, R., Ahern, A., Lipsky, E., Tasoglou, A., Sullivan, R., Bhandari, J., Mazzoleni, C., and Robinson, A. Optical properties of black carbon in cook stove emissions coated with secondary organic aerosols: Measurements and modeling. Aerosol Science and Technology (Submitted manuscript).

[12] Schwarz, J., Gao, R., Fahey, D., Thomson, D., Watts, L., Wilson, J., Reeves, J., Darbeheshti, M., Baumgardner, D., And Kok, G. Single-particle measurements of midlatitude black carbon and light-scattering aerosols from the boundary layer to the lower stratosphere. Journal of Geophysical Research: Atmospheres (1984-2012) 111, D16 (2006).

[13] Sedlacek, A. J., Lewis, E. R., Kleinman, L., Xu, J., and Zhang, Q. Determination of and evidence for non-core-shell structure of particles containing black carbon using the Single-Particle Soot Photometer (SP2). Geophysical Research Letters 39, 6 (2012).

[14] Sedlacek III, A. J., Lewis, E. R., Onasch, T. B., Lambe, A. T., and Davidovits, P. Investigation of refractory black carbon-containing particle morphologies using the single-particle soot photometer (SP2). Aerosol Science and Technology 49, 10 (2015), 872-885.

[15] Subramanian, R., Kok, G., Baumgardner, D., Clarke, A., Shinozuka, Y., Campos, T., Heizer, C., Stephens, B., De Foy, B., and Voss, P. Black carbon over Mexico: the effect of atmospheric transport on mixing state, mass absorption cross-section, and bc/co ratios. Atmos. Chem. Phys 10, 1 (2010), 219-237. 
[16] Wocken, C. A., Stevens, B. G., Almlie, J. C., and Schlasner, S. M. End-of-use technology study: An assessment of alternative uses of associated gas. Topical report for North Dakota Industrial Commission contract No. G024-052. Tech. rep., 2012. 